\title{
Injury Patterns of Pedestrians Collided with Motor Bicycles Admitted to Teaching Hospital Karapitiya
}

\author{
Mahanama $\mathrm{CT}^{1}$, Warushahennadi $\mathrm{J}^{2}$, De Silva DT ${ }^{1}$ \\ ${ }^{1}$ Office of the Judicial Medical Officer, Teaching Hospital Karapitiya, Galle, Sri Lanka \\ ${ }^{2}$ Department of Forensic Medicine, Faculty of Medicine, University of Ruhuna, Sri Lanka
}

\begin{abstract}
Introduction: Road traffic accidents involving the pedestrian are very high. This study was conducted to identify the socio-demographic characteristics, injury patterns, risk factors of pedestrians collided with motor bicycles.
\end{abstract}

Methodology: The pedestrians who get admitted to the Teaching Hospital Karapitiya following collision with motor bicycles were included.

Results: Total numbers of 432 pedestrians were included. Majority (50\%) were over 50 years. The commonest primary impact site was the legs (51\%) and the commonest injury was the compound fractures (19\%). The majority (34\%) did not have visible primary impact injuries.65\% had the primary impact injuries and those were placed $20 \mathrm{~cm}$ to $30 \mathrm{~cm}$ above the heel. Abrasion is the commonest injury present on other anatomical areas of the body. Vision and hearing problems are the risk factors of the pedestrians over the age of 70 years $(29 \%)$.The pedestrians $(56 \%)$ had collided with motor cycles while crossing the road. The majority of accidents $(67 \%)$ had occurred during the afternoon.

Conclusion: Elder pedestrians with vision and hearing problems collide with motor cycles. The common primary impact injury was found on the legs and often there were no visible injuries. The majority of the accidents occurred in the evenings while crossing the road.

Keywords: Pedestrians, Motor bicycles, Injuries, Sri Lanka

Received: 02 Dec 2019, Revised version accepted: 30 Dec 2019, Published: 31 Dec 2019. *Corresponding author: Mahanama CT, $\triangle$ Email:chamesmahanama@yahoo.com, iD https://orcid.org/0000-0002-5307-0630

Cite this article as: Samadhi DAH, Ruwanpura PR. Analysis of Injury Patterns of Motorcycle Riders Admitted to Teaching Hospital, Karapitiya, Sri Lanka. Medico-Legal Journal of Sri Lanka, 2019;7(2):73-75. DOI: http://doi.org/10.4038/mljsl.v7i2.7395

Copyright: @ 2019 with the Medico-legal Journal of Sri Lanka.

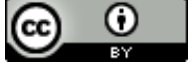

This is an open-access article distributed under the terms of the Creative Commons Attribution 4.0 International License, which permits unrestricted use, distribution and reproduction in any medium provided the original author and source are credited.

\section{Introduction}

Pedestrians involved in traffic accidents are a common casualty in hospitals in Sri Lanka. According to the Department of Census and Statistics Sri Lanka police department statistics in 2017 there were 963 pedestrian deaths out of 3147 traffic fatalities. ${ }^{[2]}$ Pedestrian fatalities in low-income countries is $45 \%$ with annual number over 200,000 and in high-income countries $18 \%$ with annual number over $22,000 \cdot{ }^{[1]}$ According to another study the majority of pedestrian crashes $(64 \%)$ along roadways occurred while the pedestrians were crossing at locations with no pedestrian crossing. ${ }^{[3]}$

When it comes to the vehicles involved in accidents, motor cycles are the commonest offending vehicle. ${ }^{[4]}$
According to the statistic of transport and civil aviation of Sri Lanka was 10147 motor cycle accidents were in 2015 which gradually increased from 2012. ${ }^{[5]}$ Therefore, the involvements of pedestrians with motor cycles are high.

The objective of this study was to determine the nature of the incident, nature and mechanism of causation of injuries and risk factors for the pedestrians admitted to a tertiary care hospital following collide with motor bicycles.

\section{Methods}

A descriptive study was conducted on pedestrians collided with motor cycles admitted to the teaching 
hospital Karapitiya from 2017 to 2019 after obtaining the ethical approval from the Ethical Review Committee of the University of Ruhuna. The informed written consent was obtained from the patients to participate in the study. Anonymous data on socio-demographic profile, type, region affected and severity of injuries and risk factors were retrieved during the forensic clinical and records examination on a pretested data sheet. Unconscious patients and patients with retrograde amnesia were excluded. The data were analyzed using SPSS IBM version 22.

\section{Results}

A total number of 432 patients were studied and $69 \%$ $(n=299)$ were male and 133 were females. The majority $26 \%(n=112)$ were between 60 to 70 years of age and the age distribution is shown in Figure 01.

Figure 01: Age distributions of the victims

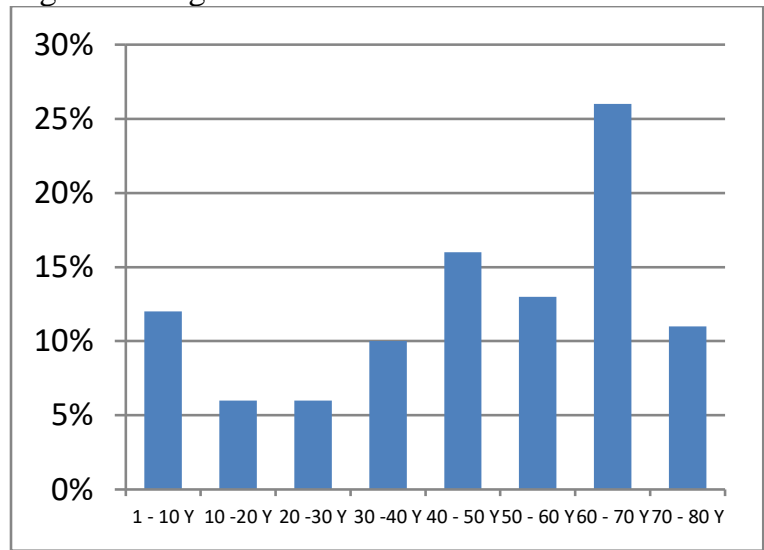

Majority (51\%) had the primary impact site on the lower limbs followed by abdomen (13\%) and the distribution is shown in Figure 02.

Figure 02: Primary impact site

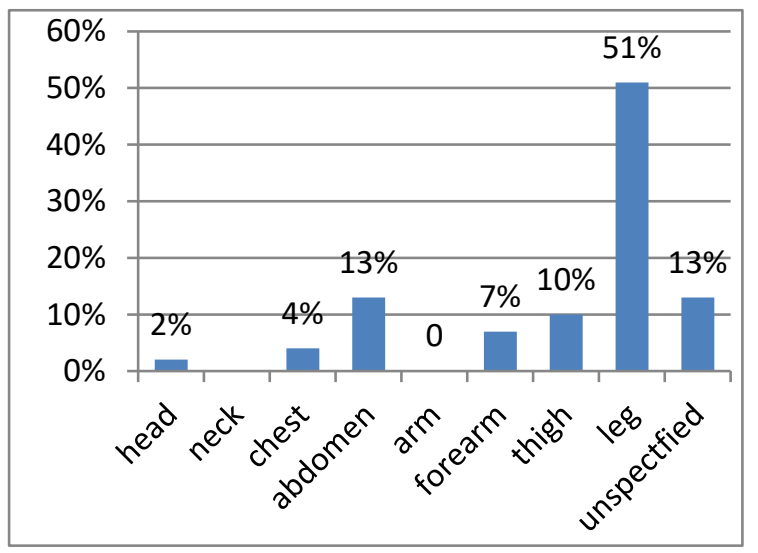

Table 01 shows the primary impact site distribution with the age. The majority of child pedestrians under the age of 10 years $(9 \%)$ had the primary impact sites in the upper parts of the body such as the chest, forearm, and head.

Table 01: Primary impact site distribution with age

\begin{tabular}{|c|c|c|c|c|c|c|c|c|}
\hline $\mathbf{P}$ & $\begin{array}{l}\text { Age } \\
01-10 \\
\%(n)\end{array}$ & $\begin{array}{l}11-20 \\
\%(n)\end{array}$ & $\begin{array}{l}21-30 \\
\%(n)\end{array}$ & $\begin{array}{l}31-40 \\
\%(n)\end{array}$ & $\begin{array}{l}41-50 \\
\%(n)\end{array}$ & $\begin{array}{l}51-60 \\
\%(n)\end{array}$ & $\begin{array}{l}61-70 \\
\%(n)\end{array}$ & $\begin{array}{r}\mathbf{N}=432 \\
71-80 \\
\%(n)\end{array}$ \\
\hline H & $02(09)$ & $00(00)$ & $00(00)$ & $00(00)$ & $00(00)$ & $00(00)$ & $00(00)$ & $00(00)$ \\
\hline $\mathbf{N}$ & $00(00)$ & $00(00)$ & $00(00)$ & $00(00)$ & $00(00)$ & $00(00)$ & $00(00)$ & $00(00)$ \\
\hline C & 03(13) & $01(02)$ & $00(00)$ & $00(00)$ & $00(00)$ & $00(01)$ & $01(02)$ & $00(00)$ \\
\hline A & $01(03)$ & $00(00)$ & $02(09)$ & $03(12)$ & $02(08)$ & $00(23)$ & $00(00)$ & $00(00)$ \\
\hline $\mathbf{U}$ & $00(00)$ & $00(00)$ & $00(00)$ & $00(00)$ & $00(00)$ & $00(00)$ & $00(00)$ & $00(00)$ \\
\hline F & 03(13) & $02(07)$ & $01(01)$ & $00(00)$ & $01(05)$ & $01(03)$ & $01(03)$ & $00(00)$ \\
\hline $\mathbf{T}$ & $00(00)$ & $00(00)$ & $01(05)$ & $01(06)$ & $01(04)$ & 03(13) & 03(11) & $01(05)$ \\
\hline $\mathbf{L}$ & 01(04) & $04(17)$ & $08(35)$ & $04(16)$ & $10(44)$ & $06(27)$ & $10(43)$ & $08(36)$ \\
\hline $\mathbf{U}$ & $02(08)$ & $00(00)$ & $00(00)$ & $01(06)$ & $01(05)$ & $02(09)$ & $02(07)$ & $05(21)$ \\
\hline
\end{tabular}

$\mathrm{P}=$ Primary impact site, $\mathrm{H}=\mathrm{Head}, \mathrm{N}=\mathrm{Neck}, \mathrm{C}=\mathrm{Chest}, \mathrm{A}=$ Abdomen, $\mathrm{U}=\mathrm{Upper}$ arm, $\mathrm{F}=$ Forearm, $\mathrm{T}=$ Thigh, $\mathrm{L}=\mathrm{Leg}, \mathrm{U}=\mathrm{Unspecified}$

$35 \%$ of the pedestrians did not have visible primary impact injuries. The commonest primary impact injury was the bone fractures (20\%). Further, all the fractures were on the legs and the majority were compound fractures $(94 \%)$ associated with lacerations. Types of primary impact injuries are shown in Table 02.

Table 02: Types of primary impact injuries

\begin{tabular}{lr}
\hline Site & $\begin{array}{r}\mathbf{N}=\mathbf{4 3 2} \\
\mathbf{\%}(\mathbf{n})\end{array}$ \\
\hline Abrasion & $13(58)$ \\
Laceration & $09(41)$ \\
Contusion & $14(59)$ \\
Fractures & $20(85)$ \\
Burns & $00(00)$ \\
None & $35(153)$ \\
Not remember & $08(36)$
\end{tabular}

When calculating the height of the primary impact injury from the heel, the majority $(65 \%)$ were between $20-30 \mathrm{~cm}$ above the heel and the distribution of the heights of primary impacts are shown in Table 03 . 
Table 03: Height of the primary impact injuries from the heel

\begin{tabular}{lr}
\hline Height from sole & $\begin{array}{r}\mathbf{N}=\mathbf{4 3 2} \\
\text { \% (n) }\end{array}$ \\
\hline $\mathbf{0 1 - 1 0 ~ c m ~}$ & $00(00)$ \\
$\mathbf{1 0 - 2 0} \mathbf{~ c m}$ & $65(112)$ \\
$\mathbf{2 1 - 3 0} \mathbf{~ c m}$ & $05(08)$ \\
$\mathbf{3 1 - 4 0} \mathbf{~ c m}$ & $03(04)$ \\
$\mathbf{4 1 - 5 0} \mathbf{~ c m}$ & $00(00)$ \\
$\mathbf{5 1 - 6 0} \mathbf{~ c m}$ & $00(00)$ \\
$\mathbf{6 1 - 7 0} \mathbf{~ c m}$ & $00(00)$ \\
$\mathbf{7 1 - 8 0} \mathbf{~ c m}$ & $00(00)$ \\
$\mathbf{8 1 - 9 0} \mathbf{~ c m}$ & $16(28)$ \\
$\mathbf{9 1 - 1 0 0} \mathbf{~ c m}$ & $11(20)$ \\
$\mathbf{1 0 1 - 1 1 0} \mathbf{~ c m}$ & $00(00)$ \\
$\mathbf{1 1 1 - 1 2 0} \mathbf{~ c m}$ & $00(00)$ \\
& \\
\hline
\end{tabular}

The commonest injury on different anatomical areas on the body as shown on the Table 04 was the abrasion.

Table 04: External injuries among the victims

\begin{tabular}{lcrrrrr}
\hline Site & $\begin{array}{r}\text { Abras } \\
\%(\mathbf{n})\end{array}$ & $\begin{array}{r}\text { Lacera } \\
\%(\mathbf{n})\end{array}$ & $\begin{array}{r}\text { Contus } \\
\%(\mathbf{n})\end{array}$ & $\begin{array}{r}\text { Fract } \\
\%(\mathbf{n})\end{array}$ & $\begin{array}{r}\text { Burn } \\
\%(\mathbf{n})\end{array}$ & $\begin{array}{r}\mathbf{N}=\mathbf{4 3 2} \\
\text { Other } \\
\%(\mathbf{n})\end{array}$ \\
\hline Head & $28(56)$ & $32(65)$ & $26(54)$ & $10(20)$ & $00(00)$ & $04(06)$ \\
Neck & $100(04)$ & $00(00)$ & $00(00)$ & $00(00)$ & $00(00)$ & $00(00)$ \\
Chest & $59(13)$ & $00(00)$ & $00(00)$ & $36(08)$ & $00(00)$ & $05(01)$ \\
Abdo & $73(11)$ & $00(00)$ & $27(04)$ & $00(00)$ & $00(00)$ & $00(00)$ \\
U.arm & $83(10)$ & $09(00)$ & $00(00)$ & $09(01)$ & $00(00)$ & $00(00)$ \\
F.arm & $64(16)$ & $16(04)$ & $00(00)$ & $20(05)$ & $00(00)$ & $00(00)$ \\
Thighs & $60(03)$ & $00(00)$ & $00(00)$ & $40(02)$ & $00(00)$ & $00(00)$ \\
Legs & $83(20)$ & $00(00)$ & $04(01)$ & $13(03)$ & $00(00)$ & $00(00)$
\end{tabular}

Abra=Abrasion, Lacera=Laceration, $\quad$ Contus=Contusions, Fract $=$ Fractures,

Table 05 shows that $99 \%$ of the pedestrians in the study had not consumed alcohol prior to the incident but $10 \%(\mathrm{n}=43)$ of pedestrians who collided with motorcycle had vision problems and $02 \%(n=08)$ had hearing problems.
Table 05: Consumption of alcohol before the accident and Correlation with diseases

\begin{tabular}{llr} 
& Variable & $\begin{array}{r}\mathbf{N}=\mathbf{4 3 2} \\
\mathbf{\%}(\mathbf{n})\end{array}$ \\
\hline Alcohol consumption & Yes & $01(03)$ \\
& No & $99(429)$ \\
& & \\
Diseases Correlation & Vision & $10(43)$ \\
& Hearing & $02(08)$ \\
& Psychiatric & $01(01)$ \\
& No above diseases & $87(380)$ \\
& & \\
\hline
\end{tabular}

According to Table 05, vision was affected in 43 pedestrians and the Table 06 shows that the group was in the age between $60-89$ yrs. Eight $(n=08)$ pedestrians had hearing problems and they were in the age group of $70-89 \mathrm{yrs}$.

Table 06: Correlation of vision and hearing with age

\begin{tabular}{lrr} 
Age & $\begin{array}{r}\text { Vision } \\
\text { \% (n) }\end{array}$ & $\begin{array}{r}\mathbf{N}=\mathbf{4 3 2} \\
\text { Hearing } \\
\mathbf{\%}(\mathbf{n})\end{array}$ \\
\hline $\mathbf{1 0 - 1 9}$ & $00(00)$ & $00(00)$ \\
$\mathbf{2 0 - 2 9}$ & $00(00)$ & $00(00)$ \\
$\mathbf{3 0 - 3 9}$ & $00(00)$ & $00(00)$ \\
$\mathbf{4 0 - 4 9}$ & $00(00)$ & $00(00)$ \\
$\mathbf{5 0 - 5 9}$ & $00(00)$ & $00(00)$ \\
$\mathbf{6 0 - 6 9}$ & $01(04)$ & $00(00)$ \\
$\mathbf{7 0 - 7 9}$ & $07(30)$ & $01(05)$ \\
$\mathbf{8 0 - 8 9}$ & $05(20)$ & $01(03)$ \\
& & \\
\hline
\end{tabular}

Half of the pedestrians (48\%) had collided with motorbike while crossing the road on locations where there was no pedestrian crossing while $30 \%$ collisions were while walking along the street (Table 7).The least number $(8 \%)$ of accidents occurred in pedestrian crossings (Table 7).Majority of pedestrians $70 \%$ have fallen after colliding with motorbikes and $28 \%$ had thrown away (Table 7). When the time of the accident was concerned $45 \%$ of the incidences occur between 12 noon and $6 \mathrm{pm}$ and $31 \%$ were between 6 am and 12 noon (Table 7).There were only $2 \%$ of accidents were between 12am and 6am (Table 7).The majorities $(55 \%)$ of injuries were non-grievous, and $42 \%$ were grievous injuries and 3\% were categorized as endangering life and the findings of this paragraph is illustrated in the Table 07. 
Table 07: Action of pedestrians 'during collision, Post-crash event, Time of incident and Category of hurt

\begin{tabular}{llr}
\hline & Variable & $\begin{array}{r}\mathbf{N = 4 3 2} \\
\mathbf{\%}(\mathbf{n})\end{array}$ \\
\hline $\begin{array}{l}\text { Action of } \\
\text { pedestrians }\end{array}$ & Standing by the side & $14(60)$ \\
& Walk along the road & $30(130)$ \\
& Walk along crossings & $08(34)$ \\
& Other than crossings & $00(00)$ \\
Post- crash & Fell & $70(305)$ \\
events & Thrown away & $28(122)$ \\
& Run over & $00(00)$ \\
& Run under & $01(05)$ \\
Time of the & 12 am-06 am & $02(09)$ \\
incident & 06 am-12 pm & $31(134)$ \\
& 12 pm-06 pm & $45(194)$ \\
& 06 pm-12 am & $22(95)$ \\
Category of & Non-grievous & $55(238)$ \\
hurt & Grievous & $42(181)$ \\
& Endangering life & $03(13)$ \\
& Fatal in ordinary & $00(00)$
\end{tabular}

\section{Discussion}

The study shows that the male pedestrians were more commonly involved in traffic accidents than the females and similar findings were observed in the literature. ${ }^{[6]}$ According to the study children and elderly people are more vulnerable pedestrians to the traffic accidents than other age groups. The dependent behavior of the children and the physical weaknesses such as hearing and visual problems may be the contributory cause among elderly people to have the higher number of accidents among extreme age groups.

Injuries most common primary impact site is legs and study of Pattern and distribution of pedestrian injuries in fatal road traffic accidental most common primary impact site is lower extremities (common injury was fracture) ${ }^{[6]}$ Our study also shows similar findings. Projection parts from the vehicle are responsible for primary impact injury. ${ }^{[7]}$ The motor cycle front wheels, the prominent part of the front wheel of which is around $25 \mathrm{~cm}$ to $30 \mathrm{~cm}$ above the ground cause primary impact with the legs. In this study the majority had the primary impact injuries on legs 20-30 am above the heel which indicates that commonest impact site was the front wheel.
It is a known fact that the alcohol is a major contributory factor in traffic injuries. According to studies done in Poland alcohol consumption among pedestrian casualties was $51.76 \% .{ }^{[8]}$ In our study, alcohol usage among pedestrians who had collided with motorbike is as low as $0.7 \%$. But the evidence of alcohol consumption was obtained from the history given by the patient, notes from the clinical records and the transfer forms which may not be accurate giving incorrect data. The absence of legal provisions for the blood alcohol analysis is a huge failure in determining level of intoxication in the victims.

According to other studies, most pedestrian accidents occur when crossing the road. ${ }^{[9]}$ Similar results were present in our study which indicates the necessity of strict road rules and change the attitude of pedestrians regarding the safe way of using the road. The most common time period of accidents was the afternoon between $12 \mathrm{pm}$ to $6 \mathrm{pm}$ which is the traffic peak hours and it is the finding in similar type of studies.

When the type of injuries were concerned the abrasion was the commonest injury which causes due to the impact with a rough surface; road. Most of the injuries in this research were non-greaves but it does not give a clear picture of prevalence of different injuries as fatal injuries were not included in the research.

This study has several limitations. We could not scientifically analyze the level of intoxication and were bound to rely on the history and the medical records which may not be accurate.

\section{Conclusions and recommendations}

Male pedestrians of extreme age groups often collide with motorbikes. Most common primary impact site is legs and commonest injury is fractures. The primary impact site is the front wheel. The pedestrians collide with motorcycles while crossing the road not pedestrian crossings. There should be strict rules and regulations regarding the use of road to pedestrians to minimize the morbidities.

\section{Disclosure statement}

Conflicts of interests: The authors declare that they have no conflicts of interests.

\section{Funding: None}

\section{References}

1. World Health Organization, Global Status Report $\begin{array}{lll}\text { on Road Safety: } & \text { WHO, }\end{array}$ 
www.who.int/violence_injury_prevention/road_s afety_status/2009/en/. [accessed on 05/11/2017]

2. Department of census and statistics-Sri Lanka. 2018. Available from: www.statistics.gov.lk. [accessed on 01/07/2018]

3. Zainb B. "Analysis of Pedestrian Crash

Characteristics and Contributing Causes in

Central Florida". Electronic Thesis and

Dissertations. 2017. [Accessed on 05.11.2017]

Available from: https://stars.library.ucf.edu/etd/ 5362

4. Kumarage AS, Wickramasinghe SM, Jayarathne P. Analysis of road accidents in Sri Lanka 2002. ISBN 955-9027-14-x. 2003 p51.

5. Department of Motor Traffic http://www.transport.gov.lk/statistic/ [access on 04/11/2017]

6. Mandal BK, Yadav BN. Pattern and distribution of pedestrian injuries in fatal road traffic accidental cases in Dharan, Nepal. Journel of Natural Science Biology and Medicine.2014;5(2): 320-3

7. Chakravarthy B, Lotfipour S, Vaca FE. Pedestrian Injuries: Emergency Care Considerations. Cal J Emerg Med. 2007; Feb; 8(1): 15-21. PMCID: PMC2859736

8. Atkins RM, Turner WH, Duthie RB, Wilde BR. Injuries to pedestrians in road traffic accidents. BMJ. 1988 Dec; 297(6661):1431-4. Doi: http://www.10.1136/bmj.297.6661.1431

9. Masoumi K, Forouzan A, Barzegari H, Asgari Darian A, Rahim F, et al. Effective Factors in Severity of Traffic Accident-Related Traumas; an Epidemiologic Study Based on the Haddon Matrix. Emerg (Tehran). 2016 Spring;4(2):78-82.

. PMCID: PMC4893755 